The Journal of SPORT, 2014, 3(2), 203-220

(C) Kent State University

\title{
Cross Cultural Differences in Consumer Evaluation of
} Cobranding in Sport

Donghun Lee

University of Houston

\section{David Pierce}

Indiana University-Purdue University Indianapolis

Kyung-O Kim

Kyungil University

Chelsie Krill

Ball State University

Nathan Felver

Ball State University 


\begin{abstract}
Brand evaluation has been studied from a cross-cultural context in recent years (Monga \& John, 2007). As a potential reason for individual differences in brand evaluations, Nisbett et al. (2001) indicated that eastern cultures generally promote holistic thinking while Western societies generally promote analytic thinking. Based on the premise of different styles of thinking, the current study examined how varying aspects of brand fit evaluation and attitude toward cobranded products impact an individual's purchase intention of cobranded products from a cross-cultural perspective. Using individuals who frequently purchase team merchandise (160 Americans and 162 Asians), two separate multiple linear regressions were performed and the overall results indicated that Americans were more likely to be influenced by brand image fit, brand quality fit, and attitude related to purchase intention of cobranded sports merchandise. In contrast, Asians were more influenced by brand quality fit, brand functionality fit, and attitude for their purchase intention. Findings from this type of research would provide practitioners and scholars with marketing insights related to how individuals evaluate cobranding practices and how cultural differences impact results in differing brand extension evaluations among global consumers of athletic team merchandise.
\end{abstract}


Brand evaluation has been studied from a cross-cultural context in recent years (Keller \& Aaker, 1992; Loken \& John, 1993; Nisbett, Peng, Choi, \& Norenzayan, 2001; Monga \& John, 2004, 2007; Yoon \& Gurhan-Canli, 2004). Brand extension is a marketing strategy used by firms to produce a product with a well-developed image using the same brand name in a different product category (Aaker \& Keller, 1990). For example, Nike recently launched Nike Plus to extend its existing product class by capitalizing its brand recognition. Cobranding, also known as dual branding (Levin, 2002) or brand alliance (Walchli, 2007), is slightly different from brand extension, and is defined as the practice of a product featuring more than one brand (Hillyer \& Tikoo, 1995). An example of cobranding in sport is Nike and Apple or Adidas and Samsung producing a wireless sensor compatible with devices such as the iPod that can track workouts for fitness enthusiasts. Lee, Kroncke, and Johnson (2012) pointed out that in the context of sport, cobranding occurs in the form of product licensing partnerships such as athletic team merchandise. They argued that "treating this type of dual branding practice as a mere licensing agreement is a myopic thinking because marketers use cobranding tactics to reposition perceptions of products, leverage consumer brand evaluations, which will ultimately contribute in increasing product sales" (p. 161).

Researchers have consistently found that cross-cultural variations exist in brand extension evaluations due to differing styles of thinking. Two paradigms, holistic and analytic thinking, explain this important consumer behavior concept. More specifically, Nisbett et al. (2001) indicated that eastern cultures often promote holistic thinking, defined as "involving an orientation to the context or field as a whole, including attention to relationships between a focal object and the field, and a preference for explaining and predicting events on the basis of such relationships" (p. 293). In contrast, Western societies often promote analytic thinking, defined as "involving detachment of the object from its context, a tendency to focus on attributes of the object to assign it to categories, and a preference for using rules about the categories to explain and predict the objects behavior" (Nisbett et al., 2001, p. 293). Consequently, due to different styles of thinking, consumers evaluate branding 
activities from different perspectives. Because sport businesses are often conducted at the global level, it is important to examine the effect of cultural differences on consumer's evaluation of branding. However, brand extension and cobranding studies, especially at the cultural level, is surprisingly lacking within the domain of sport.

Cross-cultural studies on cobranding can offer important marketing implications for businesses and sport organizations competing in today's global economy. More specifically, research on how Asians differ from Americans in their comparison of cobranding pairs that involve sport versus non-sport brands can offer important insights for enterprises who target internal consumers. This type of research would offer insights to researchers and practitioners searching for a way to approach consumers from different backgrounds. Given the recent interest of consumer behavior research in the different brand evaluations of diverse cultures (e.g. American market vs. Asian market), it is necessary to investigate if cross-cultural variation exists when consumers engage in the evaluation of cobranded sport merchandise. This need is further justified in four aspects. First, studying consumer's cobrand evaluation within the domain of sport is needed due to lack of research investigation in the existing literature. Second, empirical evidence that supports cobrand evaluation schema when sport merchandise is involved is still lacking. Third, the lack of replication of such an important consumer behavior concept within the sport domain limits generalizability of the findings. Last, researchers have criticized that most of the existing cross-cultural brand evaluation studies have exclusively been conducted toward American consumers (John, 2004; Monga \& John, 2007; Yoon \& GurhanCanli, 2004).

This study investigates whether cross-cultural differences exist when consumers evaluate cobranded athletic merchandise. Cobranding has been recognized as a relatively new business tactic that needs to be better understood as athletic merchandise continues to expand into global markets. Findings from this type of research would enable practitioners and scholars to gain marketing insights with respect to how individuals not only evaluate cobranding 
practices, but also how cultural differences impact brand evaluation among global consumers of athletic team merchandise.

\section{Review of Literature}

Theoretical Justification for Consumer Brand Evaluations in General

Categorization theory and schema congruity theory are the two theoretical bases for brand evaluation studies including the current study. Categorization theory generally indicates that consumers evaluate brand extensions based on perceived similarity (or dissimilarity) of products that are in the same (or different) category. Dawar (1996) found that the strength of association between the brand and the products it represents influences consumer brand extension evaluations. He argued that in addition to the variability, the pattern of associative strengths influences the ability of consumers to retrieve related information for processing, and thus it also influences fit judgments for the brand extension evaluation. This idea is consistent with Mervis and Rosch's (1981) concept of typicality. As products are perceived as more typical members of a category, they are more likely to be evaluated similarly. This high perceived similarity will then be translated as high fit, resulting in more positive brand extension evaluations.

Schema congruity theory is an alternative explanation for the role of "fit" in brand evaluations. Meyers-Levy and Tybout (1989) indicated that consumer's perceived congruity (or incongruity) in product attributes contributes to product evaluations. They pointed out that congruity is a function of matching whereas incongruity is a consequence of mismatch. Other researchers indicated that perceived brand fit is determined based on brand image fit (Bhat \& Reddy, 2001; Park, Jaworski, \& MacInnis, 1986). Fitness (image similarity or congruency) of two brands can be better understood from quality and functionality perspectives as well. James (2005) supported this premise by demonstrating that consumers often evaluate brand (extension) fit in terms of quality as well as functionality.

\section{Theoretical Justification for Cross-Cultural Variation}

Analytic and holistic paradigms have been adopted to understand cross-cultural differences in consumers' brand 
evaluations. More specifically, analytic thinkers, like Americans, often focus on the attributes of a product and the product's similarity to a particular category like 'sport' product in order to make judgments (Monga \& John, 2004). The literature generally indicates that the fitness of brands is judged by consumers in terms of product class similarity and attribute relevancy. For example, Nike's Band designed for sport participants as wearable 'sport' gear may be thought of by future users as a natural addition to Nike's current product classes. This implies that when evaluating a pair of brands consumers consider whether the encountered brands belong to similar product category in regards to the primary brand; additionally, consumers consider whether there is relevancy in product attributes between the encountered brands. Based on this information, consumers are likely to perceive high cobrand "fit" when high attribute relevancy and product category similarity are recognized. In contrast, consumers are likely to perceive low cobrand "fit" when low attribute relevancy and product category dissimilarity are recognized.

Holistic thinkers like Asians, however, tend to focus on relationships between objects and the field, which suggest that they are likely to consider an aspect such as complementarity as a basis of brand fit (Choi, Nisbett, \& Norenzayan, 1999). An example to this premise is that each brand in a cobranding set up complement each other and thus enhances the overall image to consumers. Choi, Nisbett, and Norenzayan further argued that as a result of this cultural variation in perceptions, consumers in the Eastern culture are more likely to judge brand fit more favorably than Westerners (i.e., analytic thinkers). Ji, Peng, and Nisbett (2000) supported this cultural difference in brand fit evaluation processes by indicating that Asians tend to be relationship dependent more than Americans, implying that the fitness of brands can be determined based on the degree of brand relationships in which holistic thinkers pay greater attention.

Based on the review of literature, the current study attempts to answer the following research questions: 1) How do varying aspects (brand image fit, brand functionality fit, brand quality fit) of brand fit impact an individual's purchase intention of cobranded 
products? 2) How does an individual's attitude toward cobranded products generally impact their purchase intention (i.e., cognitive intention to make a purchase)? Comparison of cross-cultural differences between American consumers and Asian consumers were also examined in relation to the two research questions. Attitude was defined as cognitively learned predisposition to respond to a given object (Eagly \& Chaiken, 1993).

\section{Method}

\section{Study Design, Sample, and Procedure}

The objectives of the current exploratory research were achieved in three phases: 1) pilot test I (a testing brand was identified to create cobrands), 2) pilot test II (psychometric properties of the scales measuring items towards the cobrands were examined), and 3) a main study (cross-cultural difference test was performed between Americans and Asians). Using a survey method, two convenience samples for the two pilot tests were collected from students majoring in sport administration and exercise science in a Midwestern university in the United States. From collegiate athletic events including football, basketball, and volleyball games, data were collected from the same university for a larger and more generalizable data in the main study. Using a snow-balling technique (a non-probability sampling also known as referral sampling), separate data consisting only of non-US citizens were collected from the same or similar collegiate athletic events at two other Midwestern universities over the course of three weeks (for the purpose of cross-cultural examination). To access a subpopulation who has been exposed to the same brands as most of Americans, non-US citizens residing in the US were targeted. To minimize the acculturation effect (i.e., 'Americanized') in the cross-cultural sample, non-US citizens who resided in the states less than 3 years were targeted in the current study.

Brief instructions were given to the respondents prior to distributing the questionnaires, and respondents completed a voluntary participation consent form as required by the university's Institutional Review Board. Participants were first shown a predetermined manufacturer brand (i.e., Champion) from the pilot 
study and were asked to indicate their favorite athletic team. The initial pilot testing was to identify a testing brand that is not too favorable but also recognizable to participants (refer to 'Instruments' section for more detail). Only one testing brand was used to minimize the effect of brand recognition variation. Then, the participants were asked to respond to the remaining items based on the pairing of the participant's favorite athletic team and the Champion brand, which created 'cobranding' for each of the participants. Considering Hair, Black, Babin, and Anderson's (2010) suggestion, a minimum of 150 participants were needed for the main study. The majority of the American sample $(n=160)$ consisted of individuals age between 18 and 63 years old $\left(M_{\text {age }}=28.48 ; S D=\right.$ $12.52)$, Caucasian/White $(90.0 \%)$, and male (51.9\%). The majority of the Asian sample $(n=162)$ consisted of individuals age between 18 and 44 years old $\left(M_{\mathrm{age}}=28.47 ; S D=5.25\right)$ and male $(71.0 \%)$. The ethnicity consisted of 142 Koreans, 13 Chinese, and 7 Indians.

\section{Instruments}

In the pilot test I, participants ranked 1 as the most recognizable and the 13 as the least recognizable brand. The Champion brand had the mid-level brand recognition among the thirteen existing brands (e.g. Nike, Reebok, Under Armour, Russell) and thus was chosen as a testing brand in the current study. Using this testing brand, a hypothetical cobrand scenario was created to collect data for the overall items. First, to measure varying aspects of perceived brand fit (PBFIT), Bhat and Reddy's (2001) items were slightly modified and used. More specifically, two items measuring each of the three types of brand fits were included in the instrument. The three types of brand fits were brand extension image fit, brand extension quality fit, and brand extension functionality fit.

Cronbach's alpha for the original items (brand image fit) was 0.75 .

To measure attitude toward cobranding, Laroche, Kim, and

Zhou's (1996) items were slightly modified and used. This construct was measured using three items including favorableness, likeness, and goodness. Cronbach's alpha for the original items was 0.93 or greater. To measure purchase intension of cobranded athletic team products, Hagger, Chatzisarantis, and Biddle's (2001) items were slightly modified and used (e.g. "in the future, I am likely to 
purchase more of (participant's favorite athletic team) merchandise sponsored by Champion brand"). Three items were used to measure this construct. Cronbach's alpha for the original items was 0.77 .

Data for the cross-cultural comparison was collected using the same instrument. All items were measured on a 7-point Likert-type scale in the current study. In the pilot test II of the present study, Cronbach's alpha values were identified as follows: 0.88 (brand image fit), 0.89 (brand quality fit), 0.85 (brand functionality fit), 0.73 (attitude toward cobranding), and 0.95 (purchase intention).

\section{Data Analysis}

To assess reliability and validity of the instruments, a pilot test (i.e., pilot test II) was conducted with a sample of 54 college students enrolled in two sport administration classes at a Midwestern university in the U.S. Using SPSS Version 19.0, Cronbach's alphas were calculated. Prior to the main data analyses to test cross-cultural differences, psychometric properties of the scales were reexamined. To conduct cross-cultural examinations to the extent how Americans and Asians react to cobrandings, two multiple regressions were conducted on purchase intention using both American sample and Asian sample. To minimize the type I error when running two regressions on the same variables, the alpha level was adjusted from .05 to .025 (Hair et al., 2010). Tolerance and variance inflation factor (VIF) were tested to check the multicollinearity.

\section{Results}

\section{Descriptive Statistics and Correlations}

Attitude had the highest mean in both populations while the lowest mean was found in Purchase Intention using the American sample and in Brand Image Fit using Asian sample (refer to Table $3)$. In both samples, the highest correlation was found between Brand Functionality Fit and Brand Quality Fit ( $r=.77$ in American sample and .79 in Asian sample) while the lowest correlation was found between Attitude toward Cobranding and Brand Image Fit ( $r$ $=.57$ in American sample and .42 in Asian sample; refer to Table 1). Psychometric Properties of the Instruments

In both populations, Cronbach's alphas for all variables were above .707, except for Brand Image Fit in the American sample 
(refer to Table 1). Discriminant validity among the overall variables was established in that all correlations were lower than 0.85 (Kline, 2005; refer to Table 1). While the reliability for the brand image fit when using American sample is a concern, the overall findings collectively provided evidences for good psychometric properties of the scale. Overall values for Tolerance and VIF in Table 2 indicate none severity of multicollinearity.

Table 1

Mean, Standard Deviation, Cronbach's Alpha, and Factor Correlation

\begin{tabular}{|c|c|c|c|c|c|c|}
\hline \multirow[t]{2}{*}{ Sample } & \multirow[t]{2}{*}{ Variables } & \multirow[b]{2}{*}{ BIF } & \multirow[b]{2}{*}{$\mathrm{BQF}$} & \multicolumn{3}{|c|}{ AT } \\
\hline & & & & $\mathrm{BFF}$ & $\mathrm{C}$ & PI \\
\hline \multirow[t]{8}{*}{ Americans } & Brand image fit & 1 & & & & \\
\hline & Brand quality fit & 0.73 & 1 & & & \\
\hline & $\begin{array}{l}\text { Brand functionality } \\
\text { fit }\end{array}$ & 0.68 & 0.77 & 1 & & \\
\hline & $\begin{array}{l}\text { Attitude toward } \\
\text { cobranding }\end{array}$ & 0.57 & 0.63 & 0.57 & 1 & \\
\hline & Purchase intention & 0.74 & 0.66 & 0.59 & $\begin{array}{c}0.5 \\
9\end{array}$ & 1 \\
\hline & $\alpha$ & 0.60 & 0.82 & 0.87 & $\begin{array}{c}0.8 \\
8\end{array}$ & $\begin{array}{c}0.9 \\
0\end{array}$ \\
\hline & $M$ & 4.38 & 4.52 & 4.81 & $\begin{array}{c}4.8 \\
7\end{array}$ & 4.2 \\
\hline & $S D$ & 1.27 & 1.35 & 1.17 & $\begin{array}{c}1.1 \\
7\end{array}$ & $\begin{array}{c}1.3 \\
4\end{array}$ \\
\hline \multirow[t]{8}{*}{ Asians } & Brand image fit & 1 & & & & \\
\hline & Brand quality fit & 0.72 & 1 & & & \\
\hline & $\begin{array}{l}\text { Brand functionality } \\
\text { fit }\end{array}$ & 0.76 & 0.79 & 1 & & \\
\hline & $\begin{array}{l}\text { Attitude toward } \\
\text { cobranding }\end{array}$ & 0.42 & 0.57 & 0.55 & 1 & \\
\hline & Purchase intention & 0.65 & 0.70 & 0.75 & $\begin{array}{c}0.5 \\
6\end{array}$ & 1 \\
\hline & $\alpha$ & 0.77 & 0.79 & 0.76 & $\begin{array}{c}0.8 \\
5\end{array}$ & $\begin{array}{c}0.9 \\
2\end{array}$ \\
\hline & $M$ & 2.80 & 2.85 & 2.98 & $\begin{array}{c}3.6 \\
1\end{array}$ & $\begin{array}{c}3.0 \\
8\end{array}$ \\
\hline & $S D$ & 1.38 & 1.25 & 1.34 & $\begin{array}{c}1.2 \\
9\end{array}$ & $\begin{array}{c}1.3 \\
7\end{array}$ \\
\hline
\end{tabular}




\section{Regression Analysis}

When the four independent variables were regressed on American's purchase intention of cobranded products, three variables had statistical significance at the .025 (alpha adjusted) alpha level. The three variables were Brand Image Fit, Brand Quality Fit, and Attitude toward Cobranded Products, explaining approximately $53 \%$ of the variance. At the univariate level, their coefficients were $.288, .243$, and .220 , respectively, indicating all positive influence on the purchase intention (refer to Table 2).

When a separate regression was applied toward Asian's purchase intention of cobranded products, somewhat different results were obtained. Brand Quality Fit, Brand Functionality Fit, and Attitude variables had statistical significance, explaining approximately $62 \%$ of the variance. At the univariate level, their coefficients were $.207, .385$, and .176 , respectively, indicating all positive influence on the purchase intention (refer to Table 3 ).

Table 2

Multiple Regression Results towards Americans $(N=160)$

\begin{tabular}{|c|c|c|c|c|c|}
\hline \multirow[t]{2}{*}{$\begin{array}{c}\text { Independent } \\
\text { Variables }\end{array}$} & $\begin{array}{c}\text { Standardized } \\
\text { Coefficients }\end{array}$ & \multirow[t]{2}{*}{$t$} & \multirow[t]{2}{*}{ Sig } & \multicolumn{2}{|c|}{$\begin{array}{l}\text { Collinearity } \\
\text { Statistics }\end{array}$} \\
\hline & Beta & & & $\begin{array}{c}\text { Tolera } \\
\text {-nce }\end{array}$ & VIF \\
\hline Image Fit* & .288 & $\begin{array}{l}3.2 \\
22\end{array}$ & $\begin{array}{c}.00 \\
2\end{array}$ & .419 & 2.389 \\
\hline Quality Fit* & .243 & $\begin{array}{l}2.3 \\
25\end{array}$ & $\begin{array}{c}.02 \\
2\end{array}$ & .306 & 3.266 \\
\hline $\begin{array}{l}\text { Functionality } \\
\text { Fit }\end{array}$ & .087 & $\begin{array}{c}92 \\
7\end{array}$ & $\begin{array}{c}.35 \\
6\end{array}$ & .378 & 2.646 \\
\hline Attitude* & .220 & $\begin{array}{c}2.8 \\
61\end{array}$ & $\begin{array}{c}.00 \\
5\end{array}$ & .565 & 1.771 \\
\hline
\end{tabular}

Note. Dependent Variable: Purchase intention; $\mathrm{R}^{2}=.529 ;{ }^{*}$ indicates statistical significance at the .025 level (alpha adjusted). 
Table 3

Multiple Regression Results towards Asians $(N=162)$

\begin{tabular}{|c|c|c|c|c|c|}
\hline \multirow[t]{2}{*}{$\begin{array}{l}\text { Independent } \\
\text { Variables }\end{array}$} & \multirow{2}{*}{$\begin{array}{c}\text { Standardized } \\
\text { Coefficients } \\
\text { Beta }\end{array}$} & \multirow[t]{2}{*}{$t$} & \multirow[t]{2}{*}{ Sig } & \multicolumn{2}{|c|}{$\begin{array}{c}\text { Collinearity } \\
\text { Statistics }\end{array}$} \\
\hline & & & & $\begin{array}{c}\text { Tolera } \\
\text {-nce }\end{array}$ & VIF \\
\hline Image Fit & .132 & $\begin{array}{l}1.6 \\
61\end{array}$ & $\begin{array}{c}.09 \\
9\end{array}$ & .386 & 2.590 \\
\hline Quality Fit* & .207 & $\begin{array}{l}2.3 \\
63\end{array}$ & $\begin{array}{c}.01 \\
9\end{array}$ & .320 & 3.122 \\
\hline $\begin{array}{l}\text { Functionality } \\
\text { Fit* }\end{array}$ & .385 & $\begin{array}{l}4.1 \\
64\end{array}$ & $\begin{array}{c}.00 \\
0\end{array}$ & .286 & 3.491 \\
\hline Attitude* & .176 & $\begin{array}{c}2.8 \\
65\end{array}$ & $\begin{array}{c}.00 \\
5\end{array}$ & .647 & 1.546 \\
\hline
\end{tabular}

Note. Dependent Variable: Purchase intention; $\mathrm{R}^{2}=.616 ; *$ indicates statistical significance at the .025 level (alpha adjusted).

\section{Discussion}

\section{Key Findings and Comparison to the Literature}

The current study examined the evaluation of cobranding in sports by cross-cultural consumers (i.e. Americans and Asians). Two research questions guided the current study. The first research question examined how varying aspects (brand image fit, brand functionality fit, brand quality fit) of brand fit evaluation impacted individual's purchase intention of cobranded products and if there was any cross-cultural difference. The second research question examined how individuals' attitude toward cobranded products impacted their purchase intention and if there was any cross-cultural difference. The overall findings indicated that image fit evaluation was an important consideration for American consumers' purchase intention of cobranded athletic merchandise, but it was not important for the Asian consumers. However, functionality fit was an important consideration for Asian consumers' purchase intention of cobranded athletic merchandise, but it was not important for the American consumers. These findings offer generally contrary ideas to the existing literature. For example, the literature has generally indicated that the results should have been the opposite of what was found in the current study. However, there is no complete consensus in the literature. 
There are four potential explanations why the results of this study differ from conclusions drawn in prior research. First, the current study utilized athletic merchandise and sport brands as opposed to non-sport brands typically studied in other disciplines. For example, Monga and John's (2007) brand fit evaluation study was conducted by utilizing a few hypothetical brand extensions within general consumer good category that included Kodak shoes, McDonald razor, and Mercedes-Benz watch. Unfortunately, the sport literature is devoid of any studies that have investigated consumer evaluation of athletic merchandise brands from a crosscultural perspective. As a result of these contradictory findings, there needs to be further research to generalize the consumer perspectives in cobrand evaluations of athletic merchandise. Although the athletic merchandise plays an important role in the overall sport industry, few empirical findings have offered generalizable insights to suggest implications for practitioners and researchers in the field of sport particularly in the context of cobranding (Lee, Kroncke, and Johnson, 2012).

The second factor that may explain these results is that there is a difference between examining brand extension and co-branding situations. Monga and John (2004) indicated that Americans are likely to be analytic thinkers and thus tend to focus on product attributes when evaluating brand fit. Because product attributes such as dry fit, comfortness of fabric, and/or unique color schemes are key ingredients for functionality fit evaluation in athletic brands, these elements of functionality fit should be more important for Americans than Asians when evaluating brand fit. It is worth noting that previous studies were conducted under the premise of brand extension evaluations not cobranding situations. As defined by Aaker and Keller (1990), brand extension strategies focus on the effective utilization of existing brand equity to produce a new product in a different product category, while the focus of cobranding is on the practice of brand alliance (Walchli, 2007).

Third, the sport literature has examined brand extension in the context of a team, but not in the context of athletic apparel and manufacturing. Among the few existing studies was Walsh, Chien, and Ross' (2012) team brand extension research. They indicated that 
brand extension strategies have become very common in sport, but relatively little research has been conducted in this area. They examined image fit between Taiwanese pro-baseball teams as brand extensions and their parent corporate brands, illustrating there was no strong role of fit evaluation in the overall image of corporate brands. Rather, it was found that team success had a more salient impact on the consumer's overall perception than the evaluation of image fit. Additionally, Richelieu, Lopez, and Desbordes (2008) proposed that one of the key successes of branding efforts by European soccer teams was the consumer perception of the internationalization of club operations. Their model conceptualized various stages of branding strategy that sports clubs could implement in relation to the positioning status at the level of local, regional, national and international.

Fourth, past studies have utilized analysis of variance tests to determine group differences, but this study utilized regression analysis. Monga and John (2007), for example, conducted analysis of variances to see if American consumers and Indian consumers would be different in their overall ratings of brand fit (i.e., Kodak shoes and McDonald razor). They found conflicting results in consumers' evaluation of brand fit. More specifically, they found that when prestigious brands were tested (i.e., Mercedes-Benz watch), there was no significant group difference in overall evaluation of brand fit between Americans and Indians. In contrast, they found significant group differences when less prestigious brands were tested as described above. They concluded that the significant difference in consumer brand extension evaluation between consumers in two global markets seemed to be affected by differing styles of thinking. It is worth noting that particularly from a predictive standpoint, the current sport literature lacks empirical support to generalize consumer evaluation of athletic brands because many sport and non-sport studies have looked at cross-cultural group differences by comparing mean scores (i.e., t-test, ANOVA). We believe regression has not been used in previous studies to predict consumers' connotative behavior in regards to cobranded athletic merchandise. Regression analyses were used in the current study to predict respondents' intention to purchase hypothetically generated 
cobranded athletic products. Up to $62 \%$ of variance was explained by the chosen brand fit measures.

It is worth note that this research highlights the need for cross-cultural research on branding especially within the realm of athletic merchandise. In sum, the current study offers insights to the consumer evaluation of cobranded athletic merchandise at the crosscultural level. This type of research needs to be continued at the cross-cultural level, especially in developing countries where more business opportunities await.

\section{Limitations and Recommendations}

Several limitations were identified, and recommendations were made for future research. Use of one sample from each culture may not be sufficient to represent each culture. The Asian sample was heavily populated with Koreans and thus the cross-cultural results were not generalizable onto the broader Asian culture. In order to increase generalizability, using multiple samples from various cultures and comparing the overall findings will be ideal. In addition, data collection using different athletic brands, preferably athletic brands with different levels of brand recognition (e.g. Nike, New Balance, Russell, and Champion) will increase generalizability. The literature generally indicates that brand evaluation "differences are robust for extensions that range from very low to moderate fits with the parent brand" (Monga \& John, 2007, p. 535). By the same token, testing consumer evaluation of cobranding with varying levels of fit will likely make a greater contribution to the sport literature. Future research should thus incorporate globally recognized brand as well as moderately (or poorly) recognized athletic brands in the same study. 


\section{References}

Aaker, D. A., \& Keller, K. L. (1990). Consumer evaluations of brand extensions. Journal of Marketing, 54, 27-41.

Bhat, S., \& Reddy, S. K. (2001). The impact of parent brand attribute associations and affect on brand extension evaluation. Journal of Business Research, 53, 111-122.

Campbell, R. M. Jr., \& Kent, A. (2002). Brand extension evaluation: The case of NFL Europe. Sport Marketing Quarterly, 11(2), 117-120.

Choi, I., Nisbett, R. E., \& Norenzayan, A. (1999). Causal attribution across cultures: Variation and universality. Psychological Bulletin, 125(1), 47-63.

Dawar, N. (1996). Extensions of broad brands: The role of retrieval in evaluations of fit. Journal of Consumer Psychology, 5(2), 189-207.

Eagly, A., \& Chaiken, S. (1993). The psychology of attitudes. Fort Worth: Harcourt Brace Jovanovich College.

Estimated retail sales in U.S. and Canada. (2007, August 13). Street \& Smith's Sports Business Journal, p. 19.

Hagger, M. S., Chatzisarantis, N., \& Biddle, S. J. H. (2001). The influence of self-efficacy and past behavior on the physical activity intentions of young people. Journal of Sports Sciences, 19, 711-725.

Hair, J. F., Black, W. C., Babin, B. J., Anderson, R. E. (2010). Multivariate data analysis (7th ed.). Upper Saddle River, NJ: Prentice Hall.

Hillyer, C., \& Tikoo, S. (1995). Effect of cobranding on consumer product evaluations. Advances in Consumer Research, 22, 123-127.

James, D. (2005). Guilty through association: Brand association transfer to brand alliances. Journal of Consumer Marketing, 22(1), 14-24.

Ji, L-J., Peng, K., \& Nisbett, R. E. (2000). Culture, Control, and Perception of Relationships in the Environment. Journal of Personality, and Social Psychology, 78(5), 943-955. 
Keller, K. L., \& Aaker, D. A. (1992). The effects of sequential introduction of brand extensions. Journal of Marketing Research, 26, 35-50.

Kim, C., \& Heere, B. (2012). Consumers from emerging markets: Perceptions and attitudes toward global sporting brands. Sport Marketing Quarterly, 21, 19-31.

Kline, R. B. (2005). Principles and Practice of Structural Equation Modeling. New York: The Guilford Press.

Laroche, M., Kim C., \& Zhou, L. (1996). Brand familiarity and confidence as determinants of purchase intention: An empirical test in a multiple brand context. Journal of Business Research, 37, 115-120.

Lee, D., Kroncke, C., \& Johnson, J, E. (2012). Consumer evaluation of brand fit, attitude, and purchase intention of athletic team merchandise. International Journal of Sport Management and Marketing, 11(3/4), 158-171.

Levin, A. M. (2002). Contrast and assimilation processes in consumers' evaluations of dual brands. Journal of Business and Psychology, 17(1), 145-154.

Loken, B., \& Roedder, J. D. (1993). Diluting brand beliefs: When do brand extensions have a negative impact? Journal of Marketing, 57, 71-84.

Mervis, C. B., \& Rosch, E. (1981). Categorization of natural objects. Annual Review of Psychology, 32, 89-115.

Meyers-Levy, J., \& Tybout, A. M. (1989). Schema congruity as a basis for product evaluation. Journal of Consumer Research, $16,39-54$.

Monga, A. B., \& John, D. R. (2007). Cultural differences in brand extension evaluation: The influence of analytic versus holistic thinking. Journal of Consumer Research, 33, 529536.

Monga, A. B., \& John, D. R. (2004). Consumer response to brand extensions: Does culture matter? Advances in Consumer Research, 31, 216-222.

Nisbett, R. E., Peng, K., Choi, I., \& Norenzayan, A. (2001). Culture and systems of thought: Holistic versus analytic cognition. Psychological Review, 108, 291-310. 
Park, C. W., Jaworski, B. J., \& MacInnis, D. J. (1986). Strategic brand concept-image management. Journal of Marketing, 50, $135-145$.

Richelieu, A., Lopez, S., \& Desbordes, M. (2008). The internationalization of a sports team trend: The case of European soccer teams. International Journal of Sports Marketing \& Sponsorship, 10(1), 29-44.

Roedder, J. D., Loken, B., \& Joiner, C. (1998). The negative impact of extensions: Can flagship products be diluted? Journal of Marketing, 62, 19-32.

Walchli, S. B. (2007). The effects of between-partner congruity on consumer evaluation of co-branded products. Psychology \& Marketing, 24(11), 947-973.

Walsh, P., Chien, C-I. J., \& Ross, S. D. (2012). Sport teams as brand extensions: A case of Taiwanese baseball. Sport Marketing Quarterly, 21, 138-146.

Yoon, Y., \& Gurhan-Canli, Z. (Eds.). (2004). Cross-cultural differences in brand extension evaluations: The effect of holistic and analytical processing. Advances in Consumer Research, 31, 2 